\title{
APPLICATION CHARACTERISTICS AND RESEARCH DIFFICULTIES OF COILED TUBING DRILLING TECHNOLOGY
}

\author{
SY Quan \\ SWPU, Cengdu, China
}

\author{
YQ Xia \\ SWPU, Cengdu, China
}

\begin{abstract}
With the increase in the number of oil and gas wells and well depth, coiled tubing drilling technology has developed rapidly, especially the breakthrough progress in oil and gas transportation has improved the safety and reliability of operations. Coiled tubing mainly uses nonthreaded connections to complete tasks such as workover, logging, drilling, and completion. It has high efficiency, low cost, diversity, and a broad application market. This paper deeply analyzes the operational advantages and application difficulties of coiled tubing by studying the current application and application characteristics of coiled tubing drilling technology at home and abroad.
\end{abstract}

Keywords - Coiled tubing; technical status; operational advantages; failure modes; development trend

\section{INTRODUCTION}

The traditional underground oil and gas operation uses wells and single oil pipes, which has a long operating cycle and high accident rate, which is easy to cause secondary pollution of oil and gas. Compared with traditional drilling, coiled tubing achieves safe and fast operation, and continuous belt press operation can improve work efficiency, reduce labor intensity and operating cost, and reduce damage to oil wells. At the same time, coiled tubing has greater advantages in mining special wells, complex wells, directional drilling, underbalanced drilling and small wellbore applications, and has outstanding highlights in ultra-deep well operations[1,2].

\section{DOMESTIC AND INTERNATIONAL APPLICATION STATUS}

\section{A. FOREIGN STATUS}

Coiled tubing originated during World War II, the Allied forces used 17 special metal pipelines to transport oil across the sea and successfully crossed the English Channel; in the 1990s, foreign countries ushered in a development boom; in 2014, the annual output of global coiled tubing increased by $10 \%$ per year. The rate exceeded 3,000 units, the downhole operation volume increased by $25 \%$, the annual consumption was nearly 5 million meters, and the continuous oil pipe

\author{
YY Zeng \\ SWPU, Cengdu, China \\ J Chen \\ SWPU, Cengdu, China
}

collection, gas and liquid integration realized diversified operations and was widely used[3].

At present, foreign coiled tubing drilling technology has been scaled up. The world's three major manufacturing companies, led by the US Precision Tubing Technology Company, are the world's major equipment suppliers. The number of applications in North America accounts for more than $85 \%$ of the world's total. In the western working area of Pradesh Bay, USA, the annual coiled tubing used more than 1000 wells[4]; in 2001, the US Columbia Gas Transmission Company successfully completed sidetracking in the Donegal gas storage field using coiled tubing drilling equipment; Dreco Canada developed a kind for the Arctic Or the coiled tubing machine in the desert area can withstand the extreme temperatures of ultra-low temperature and ultra-high temperature[5].

\section{B. DOMESTIC STATUS}

Due to the uneven development of oilfield resources in various regions, the imperfection of coiled tubing equipment and the limitations of materials and processing technology, China's coiled tubing drilling technology is still in the development stage, with more than 160 coiled tubing for routine operations such as workovers[6]. Work machine, but in the research and development technology, innovation theory and equipment and equipment did not form a complete and complete functional system, the actual application has great difficulties.

In 1978, the Sichuan Petroleum Administration

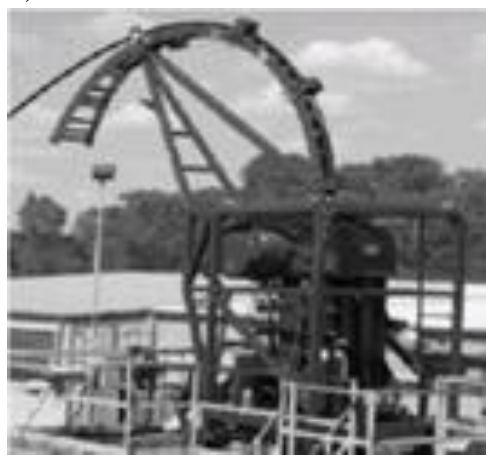

Fig.1.Coiled tubing injection head[7] 


\section{International Journal of Engineering Applied Sciences and Technology, 2019 Vol. 4, Issue 6, ISSN No. 2455-2143, Pages 187-189 \\ Published Online October 2019 in IJEAST (http://www.ijeast.com)}

introduced the first coiled tubing operation machine from the US company Bonn for workover operations. In 2008, Jianghan Oilfield No. 4 Machinery Plant started the coiled tubing series R\&D project, successfully developing and designing, independent machine assembly. And the complete production process of safe production; in 2012, a well string in Shanxi Jincheng completed the card release, expanding the operation field to the field of coalbed methane[8]; in 2016, CNPC invented a coiled tubing injection head support device to avoid coiled tubing bending, To reduce the loss of force and increase the distance of the cleanable collecting pipe network.

\section{OPERATION ADVANTAGE}

Coiled tubing drilling technology has many irreplaceable advantages over conventional operating tools[9]:

1. The coiled tubing can be sent to the target operation section from the wellhead at one time. The operation is simple and the equipment is simple. It can realize continuous drilling without connecting by pipe, increasing the drilling speed, shortening the drilling cycle and reducing the labor intensity.

2. Coiled tubing has the characteristics of no variable diameter, large bending, high strength and high pressure. It provides safe and reliable technical means for short-radius, large-displacement, multi-lateral horizontal drilling, and underbalanced and small borehole drilling.

3. The coiled tubing can complete the operation without removing it due to the small diameter, realizing the synchronous movement and fluid transport, reducing the downhole operation time and improving the work quality;

4. a wide range of operations, in addition to conventional workover, can be used with other supporting equipment to achieve underground sand washing, wax cleaning, acidification, fracturing and logging, drilling and other special downhole operations, in horizontal wells and micro-hole operations.

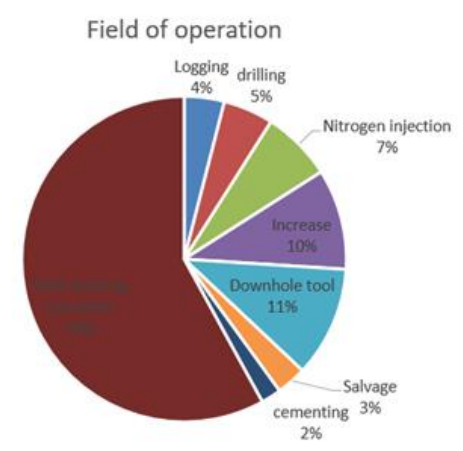

Fig.2.Coiled tubing application profile

5. small footprint, fast handling and installation, cable can be built, automatic control and measurement while drilling, improve drilling safety, reduce operators and reduce drilling costs.

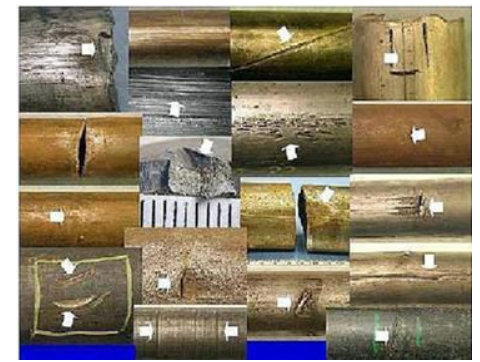

Fig.3.Coiled tubing failure diagram[10]

\section{RESEARCH AND APPLICATION DIFFICULTIES}

\section{A.MATERIAL PROBLEM}

The manufacturing materials of the coiled tubing often have disadvantages such as low strength and poor corrosion resistance, resulting in short service life of the coiled tubing and low operational reliability. In manufacturing and downhole operations, due to the uneven wall thickness of the tubing, the traditional welding process is very likely to cause weld failure mainly due to fracture failure, causing internal defects of the tubing, reducing the impact toughness of the material and affecting the normal operation of the tubing. It is easy to cause a safety accident.

\section{B. FAILURE FORM}

The underground working environment is harsh, the force is complicated, and the tubing failure forms are various. The failure of the tubing is mainly caused by material properties, working environment, use management and human factors. It is found that the failure mainly consists of deformation failure, fracture failure, fatigue failure, corrosion failure and surface damage failure.

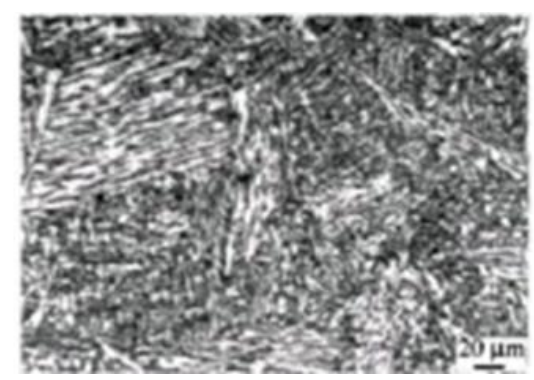

Fig.4.Welding microstructure map[11]

In the main failure behavior of the tubing, fatigue failure accounts for about $15 \%$ [12]. In the continuous operation, it is necessary to continuously inject and lift out the wellbore, and a large amount of alternating cyclic stress acts on the oil pipe, so that it is repeatedly bent and straightened. Low cycle fatigue damage is produced, which ultimately leads to fatigue failure, mechanical properties are significantly reduced, and work efficiency is greatly reduced. Although a specified amount of corrosion inhibitor and sulfur removal agent are 


\section{International Journal of Engineering Applied Sciences and Technology, 2019 Vol. 4, Issue 6, ISSN No. 2455-2143, Pages 187-189 \\ Published Online October 2019 in IJEAST (http://www.ijeast.com)}

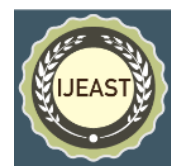

injected, in high-corrosion working environment, especially acidic environment, such as hydrogen sulfide, salt water, acid suppression, and even atmospheric exposure, the corrosion of the coiled tubing in complex working conditions will be aggravated. causing corrosion failure[13]. In addition to electrochemical corrosion, it also includes other complex acid corrosion, resulting in reduced ductility of the coiled tubing, which is highly susceptible to corrosion and fracture.

\section{Immature application technology}

At present, China's coiled tubing drilling technology has been gradually upgraded from the early single operation, broadening the application field, and has a complete coiled tubing drilling operation technology, and tends to diversify and automate development. In the actual operation process, the downhole application technology based on multi-stage fracturing and long horizontal wells has reached the international level, but it has not been able to combine the actual geological characteristics of major oil and gas fields to form a supporting technical standard system. More is only the study of theoretical technology or the blind introduction of foreign operating equipment, resulting in waste of resources, no improvement in core technology and improvement of manufacturing processes[14].

\section{Unsound production management system}

In China's practical application, there is a lack of advanced production management system, that is, from the design, research and development, production of coiled tubing and supporting equipment, to the strict management of various indicators in actual underground operations, and finally to the real-time supervision and maintenance of the entire process, staff The security protection, operational problem feedback and other aspects are manifested as single management, standard confusion and other issues[15]. Due to the lack of production chain of related equipment, there is no unified system for quality supervision and management of materials. Non-standardized production will lead to uncertainty in actual operation. At the same time, in the absence of advanced production management system, actual operations are often subject to natural or artificial Due to the influence of factors, the pretreatment scheme cannot be implemented in time, the degree of automation is low, the production process is unstable, the capacity upgrade is slow, the routine production operation cycle is delayed, and the economic cost is increased.

Acknowledgements :

This work is supported by the Chengdu Science and Technology Plan (2019-GH02-00072-HZ)

\section{REFERENCES}

[1] Han Chuanjun Zhang.Jie Liu Yang. Thermal-structure coupling analysis for general stator lining of PDM[J]. Journal of Central SouthUniversity : Science and Technology ,2013,44(6) : 23H-2317.

[2]Caroline Eulino Gonçalves Pereira,Experimental analysis of pressure drop in the flow of Newtonian fluid in coiled tubing,Journal of Petroleum Science and Engineering, Volume 179,2019,Pages 565-573.

[3] Liu He . Hao Xianzhong. Wang Liangang.et al. Current technicalstatus and development trend of artificial li!t[J]. Acta PetrolciSinica,20 15,36(H ) : 1441-1448.

[4] Kevin Cox,Analysis of flexible composites for coiled tubing applications,Composite Structures,Volume 225,2019,111118.

[5] Feng Guan,An experimental study of mechanical behavior of coiled tubing in pipelines, Applied Ocean Research,Volume 44,2014,Pages 13-19.

[6] Bill Aitken,Coiled tubing software models and field applications - A review,Journal of Petroleum Science and Engineering,Volume 182,2019,106308.

[7] SHI Guo-chen. Theperformanceanalysisand thematching technologyre search ofprogressing cavity pump foroilproduction[D]. HarbinInstituteofTechnology, 2002.

[8] YEW ei-dong, HAN Dao-quan , SONG Yu-jie , eta1.Contactingpressure analysis of statorand rotor of progressive cavity pump. OilField Equipment , 2008, 37(8): 25-28.

[9] Kevin Cox,Analysis of flexible composites for coiled tubing applications,Composite Structures, Volume 225,2019,111118

[10] Guanghui Zhao,A study on ductile fracture of coiled tubing based on cohesive zone model,Engineering Fracture Mechanics, Volume 209,2019,Pages 260-273

[11] Chapter Ten - Coiled Tubing Well Control,Editor(s): Howard Crumpton,Well Control for Completions and Interventions, Gulf Professional Publishing,2018,Pages 483566

[12] Feng Guan,An experimental study of mechanical behavior of coiled tubing in pipelines,Applied Ocean Research,Volume 44,2014,Pages 13-19

[13] Wenping Zhang, Mechanism analysis of friction reduction in coiled tubing drilling with axial vibratory tool,Journal of Petroleum Science and Engineering,Volume 175,2019,Pages 324-337

[14] Bill Aitken,Coiled tubing software models and field applications - A review,Journal of Petroleum Science and Engineering,Volume 182,2019,106308

[15] Xing Qin, The effect of residual bending on coiled tubing buckling behavior in a horizontal well,Journal of Natural Gas Science and Engineering,Volume 30,2016,Pages 182-194 